\title{
Má oclusão Classe I de Angle, com acentuada biprotrusão, tratada com extrações de dentes permanentes*
}

\author{
Marco Antônio Schroeder ${ }^{\star *}$
}

\begin{abstract}
Resumo
Este relato de caso descreve o tratamento de uma má oclusão do tipo Classe I de Angle que apresentava biprotrusão dentária e os dentes 16, 26 e 47 com as coroas destruídas. O caso foi tratado em duas fases, sequencialmente, e, com o objetivo de corrigir a biprotrusão, extrações dentárias foram necessárias. Na primeira fase, foram feitas as extrações dos dentes 16, 26, 37 e 47 e, na segunda fase, as extrações dos dentes 14, 24, 34 e 44. Esse caso foi apresentado à Diretoria do Board Brasileiro de Ortodontia e Ortopedia Facial (BBO), representando a categoria 2, ou seja, uma má oclusão Classe I de Angle tratada com extrações de dentes permanentes, como parte dos requisitos para a obtenção do título de Diplomado pelo BBO.
\end{abstract}

Palavras-chave: Má oclusão de Angle Classe I. Extração dentária. Ortodontia Corretiva.

\section{HISTÓRIA E ETIOLOGIA}

A paciente se apresentou para o exame inicial aos 23 anos, com bom estado geral de saúde. Sua história médica e odontológica não possuía registros significativos. Não era portadora de posicionamento lingual anormal durante os movimentos funcionais de deglutição ou fonação. Sua queixa principal era a protrusão labial (Fig. 1) e queria saber, também, da possibilidade de extrair e fechar os espaços de alguns dentes posteriores que estavam destruídos, ao invés de iniciar o tratamento restaurador dos mesmos.

\section{DIAGNÓSTICO}

Apresentava ANB igual a $4^{\circ}\left(\mathrm{SNA}=85^{\circ} \mathrm{e} \mathrm{SNB}\right.$ $=81^{\circ}$ ), crescimento mandibular levemente diminuído no sentido vertical $\left(F M A=29^{\circ}\right.$ e eixo $\mathrm{Y}=$ $60^{\circ}$ ) e maxila protruída em relação à mandíbula e à base do crânio (ângulo de convexidade $=9^{\circ}$ ). Essas informações podem ser melhor avaliadas na figura 4 e na tabela 1.

Quanto ao aspecto dentário, como pode ser observado nas figuras 1 e 2, era portadora de uma má oclusão Classe I de Angle, sobremordida e sobressaliência de $2 \mathrm{~mm}$, linha média inferior e superior 

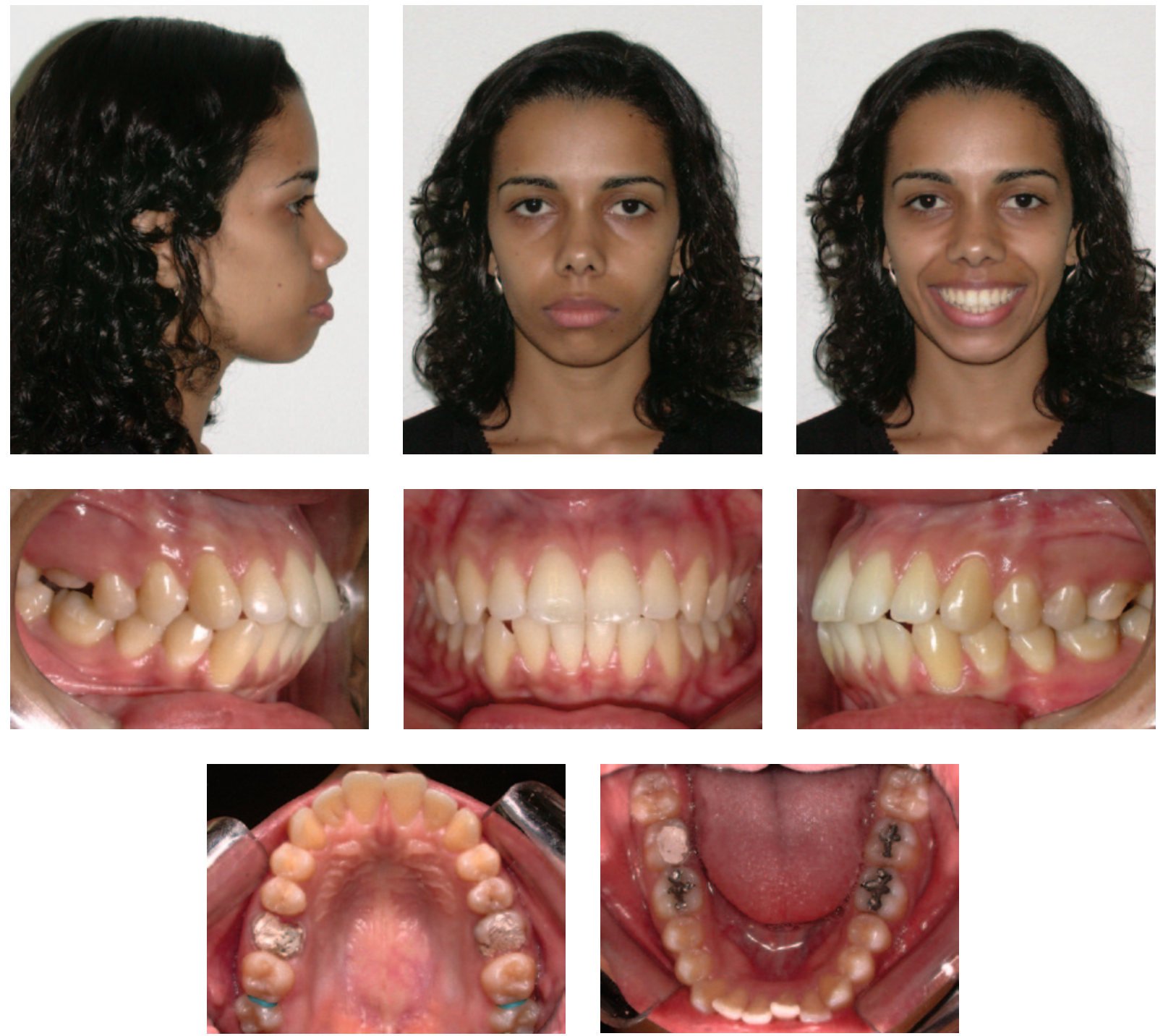

FIGURA 1 - Fotografias faciais e intrabucais iniciais.

coincidentes, coroas dos dentes 16, 26 e 47 com grande destruição, arcos parabólicos, apresentando simetria nos sentidos anteroposterior e transverso, discrepância de perímetro do arco inferior de $-4 \mathrm{~mm}$ e ausência de discrepância de Bolton. Em relação ao perfil facial, apresentava acentuada biprotrusão labial.

$\mathrm{Na}$ avaliação das radiografias periapicais (Fig. 3B), foi possível observar extensa destruição das coroas dos dentes 16, 26 e 47; raízes longas e com dilaceração nos dentes 12, 34, 38 e 47; e trabeculado ósseo com aspecto normal. $\mathrm{Na}$ avaliação da radiografia cefalométrica de perfil (Fig. 4), observou-se vias aéreas superiores desobstruídas, boa inclinação do plano mandibular, incisivos com inclinação excessiva para vestibular e perfil convexo.

\section{OBJETIVOS DO TRATAMENTO}

Na maxila e na mandíbula, buscou-se manter o posicionamento vertical e transverso, tanto da 

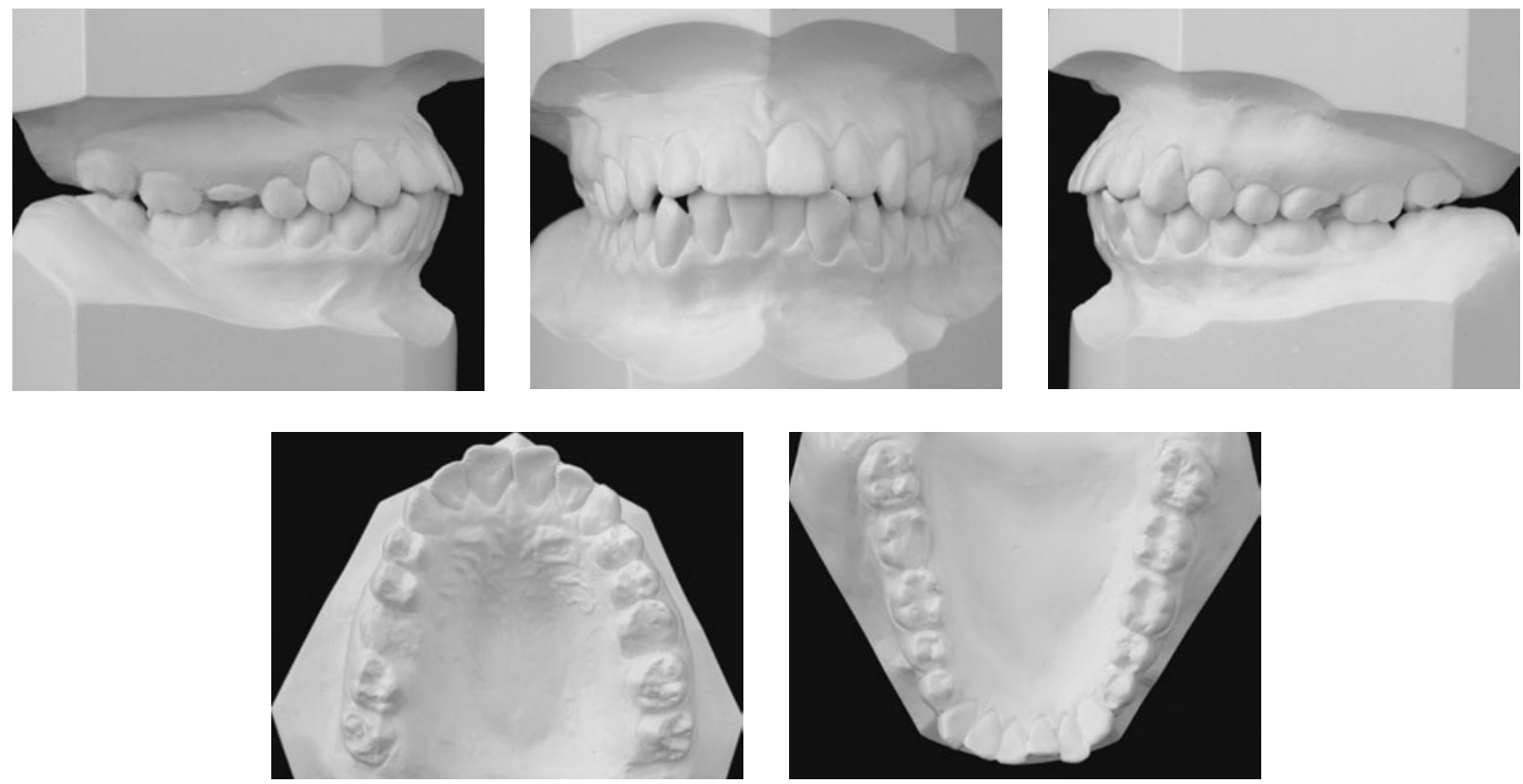

FIGURA 2 - Modelos iniciais.
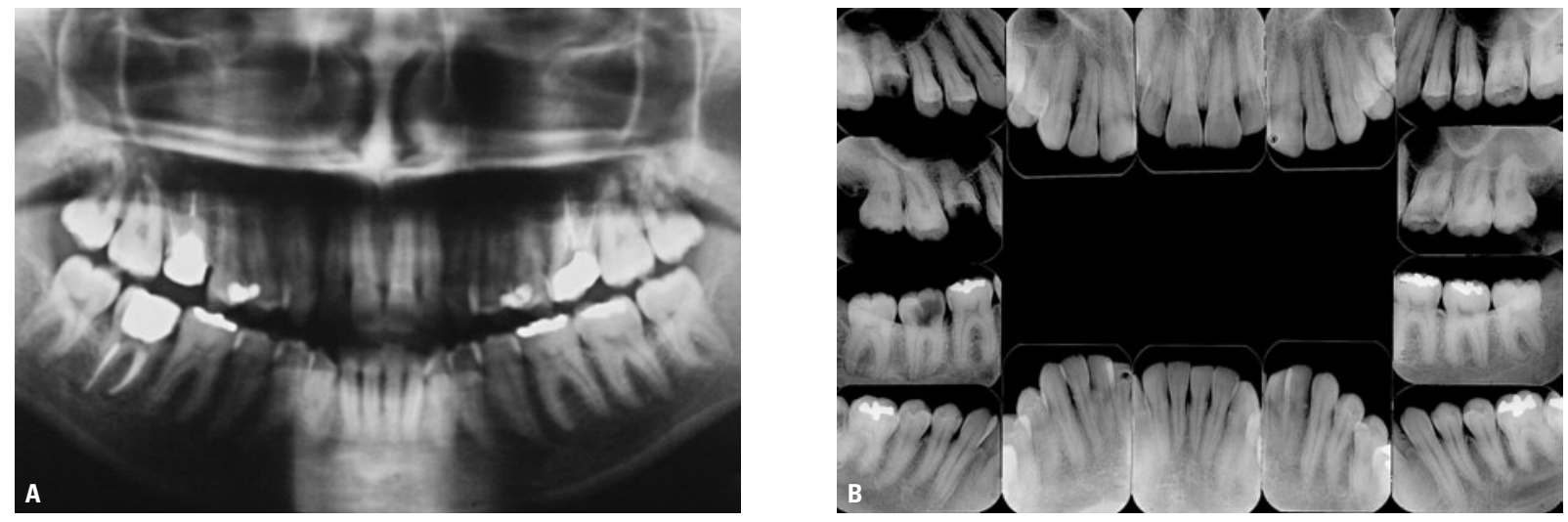

FIGURA 3 - Radiografias panorâmica (A) e periapicais iniciais (B).
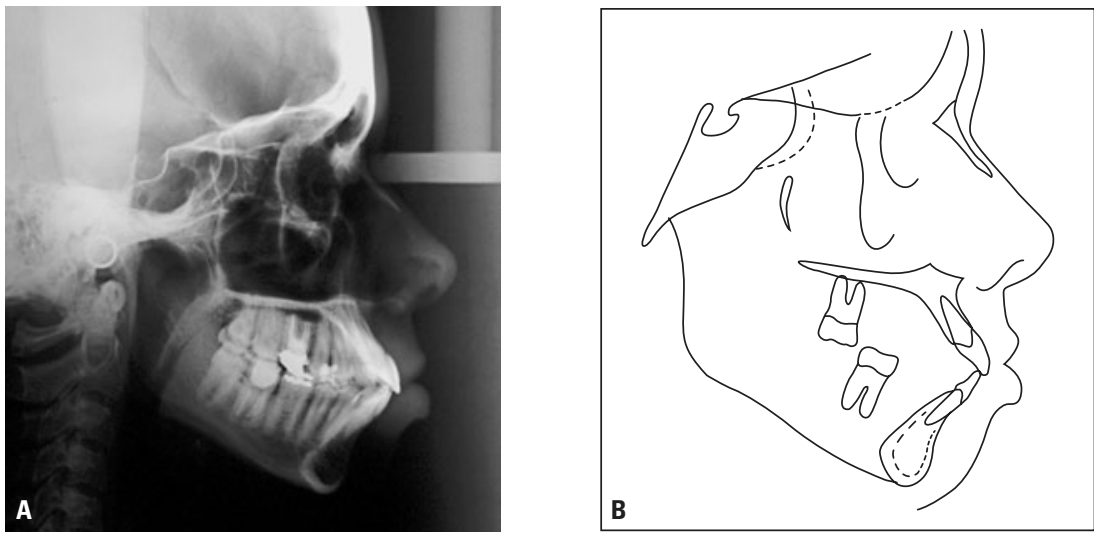

FIGURA 4 - Radiografia cefalométrica de perfil (A) e traçado cefalométrico (B) iniciais. Em B, observa-se que foram traçados os segundos molares superiores em função da exodontia dos primeiros. 
base óssea quanto da dentição, reduzir a biprotrusão dentária, estabelecer correta inclinação para os incisivos, obter nova relação de chave de oclusão nos molares, estabelecer adequada sobremordida e sobressaliência e guias de desoclusão. Com a redução da protrusão dentária, esperava-se melhora significativa na convexidade do perfil.

\section{PLANO DE TRATAMENTO}

Como a paciente não concordou com a colocação de ancoragem esquelética, foi explicado que, para reduzir a protrusão dentária de modo que houvesse melhora na convexidade do perfil, o tratamento poderia necessitar de uma segunda fase. Na primeira fase, seriam feitas as extrações dos dentes 16, 26, 37 e 47, e os espaços seriam fechados, mas a protrusão dentária, provavelmente, só seria corrigida completamente em uma segunda fase, com a extração dos dentes 14, 24, 34 e 44.

Planejou-se a montagem de aparelho ortodôntico fixo nos arcos dentários superior e inferior, sistema Edgewise, standard, slot 0,022" x 0,028", e arcos de níquel-titânio até $0,016 "$, para alinhamento e nivelamento, seguidos dos arcos de aço inoxidável 0,018". A partir dos arcos de aço inoxidável 0,018 ", superior e inferior, seria iniciado o fechamento dos espaços obtidos com as extrações dos primeiros molares superiores e dos segundos molares inferiores, dente a dente, de mesial para distal. Como ancoragem superior, planejou-se a utilização do botão de Nance associado ao aparelho extrabucal de Kloehn (AEBK) - para manutenção dos segundos molares superiores em posição - e mecânica de Classe III, apoiada no AEBK, para evitar projeção dos dentes anteroinferiores.

Após o fechamento dos espaços dos molares, caso houvesse necessidade, em função do perfil da paciente, seria solicitada a exodontia dos primeiros pré-molares superiores e inferiores, seguida de movimentação para distal dos caninos, individualmente, e retração dos dentes anteriores, tanto no arco dentário superior quanto no inferior.

Para a finalização, seriam utilizados arcos retangulares $0,019 " \times 0,025$ ", superior e inferior, com dobras de primeira e terceira ordens, individualizadas de acordo com a necessidade. Após a fase de tratamento ativo, planejou-se a utilização de uma placa de contenção superior removível (wraparound) e, no arco inferior, de uma barra confeccionada com fio Twist Flex 0,018”, colada do dente 35 ao 45 .

\section{PROGRESSO DO TRATAMENTO}

Foram instalados anéis ortodônticos nos segundos molares superiores, nos quais foi adaptado o botão de Nance, associado ao AEBK, para ancoragem dessas unidades. Foi, então, solicitada a exodontia dos dentes 16, 26 e 47, que apresentavam grande comprometimento coronário, e do dente 37. Em seguida, foi montado o restante do aparelho ortodôntico fixo nos arcos dentários superior e inferior, sistema Edgewise, standard, com slot $0,022 "$ x $0,028 "$.

Para o alinhamento e nivelamento, foram instalados, sequencialmente, nos arcos dentários superior e inferior, arcos de níquel-titânio até 0,016 ", seguidos de arcos 0,018" de aço inoxidável. A partir desse arco, foi iniciado o fechamento dos espaços, dente a dente, utilizando-se elástico em cadeia, nos arcos dentários superior e inferior. O ômega foi mantido levemente afastado do tubo dos segundos molares superiores e terceiros molares inferiores, e foi realizado tie together nos dentes posteriores, à medida que os espaços foram se fechando. Para ancoragem inferior, foi utilizada mecânica de Classe III. Após a retração dos primeiros pré-molares, foi removido o botão de Nance e instalou-se arco de aço inoxidável 0,018 ” x 0,025 ”, com alça em forma de "T", para retração dos seis dentes anteriores superiores e inferiores. Durante todo o fechamento dos espaços, incorporou-se uma curva reversa, no arco inferior, e acentuada, no arco superior, para controle da sobremordida. Além disso, acentuou-se o tip back nos molares inferiores, para controle da inclinação dos mesmos para mesial e, também, como reforço de ancoragem. 

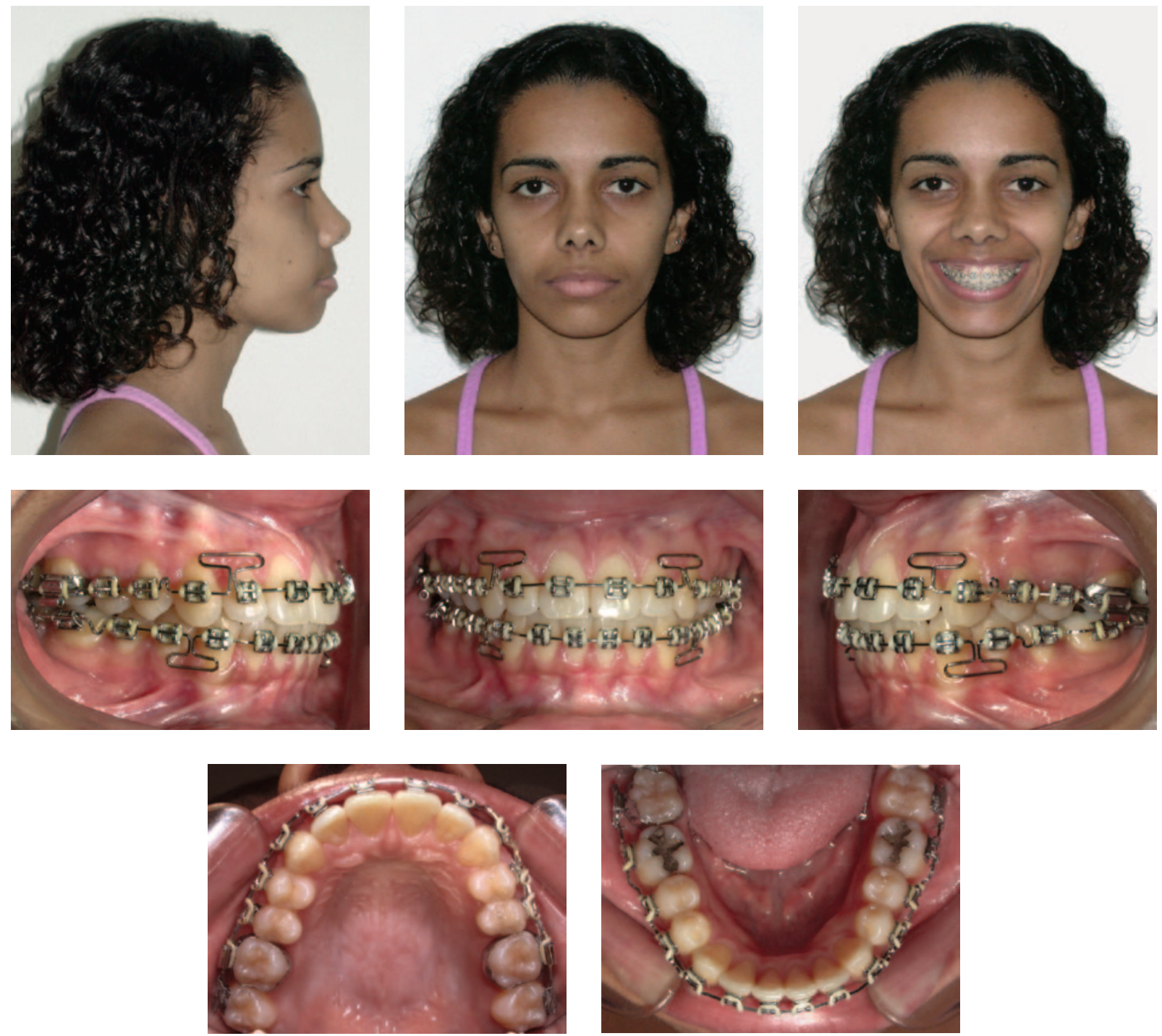

FIGURA 5 - Fotografias faciais e intrabucais intermediárias.

Após o fechamento dos espaços dos molares (Fig. 5), foi realizado um reestudo do caso (Fig. 6, 7), quando verificou-se que houve movimentação para distal do primeiro molar inferior e para mesial do segundo molar superior, e pouca retração dos incisivos superiores e inferiores, o que gerou pequena alteração no perfil (Fig. 9). Dessa forma, para se obter a completa redução da biprotrusão dentária, houve a necessidade de solicitar a exodontia dos dentes 14, 24, 34 e 44 (Fig. 8).
Em seguida, no arco dentário superior, iniciou-se a movimentação para distal dos dentes 13 e 23, utilizando-se arco 0,018" de aço inoxidável e, no arco dentário inferior, confeccionou-se novo arco com alça em forma de "T", agora com fio retangu$\operatorname{lar} 0,019$ ” x 0,025”, para retração dos seis dentes anteriores. Após a movimentação para distal dos dentes 13 e 23, foi utilizado arco com alça, confeccionado com fio 0,019 " x 0,025 ", para retração dos incisivos superiores. Após o fechamento dos 

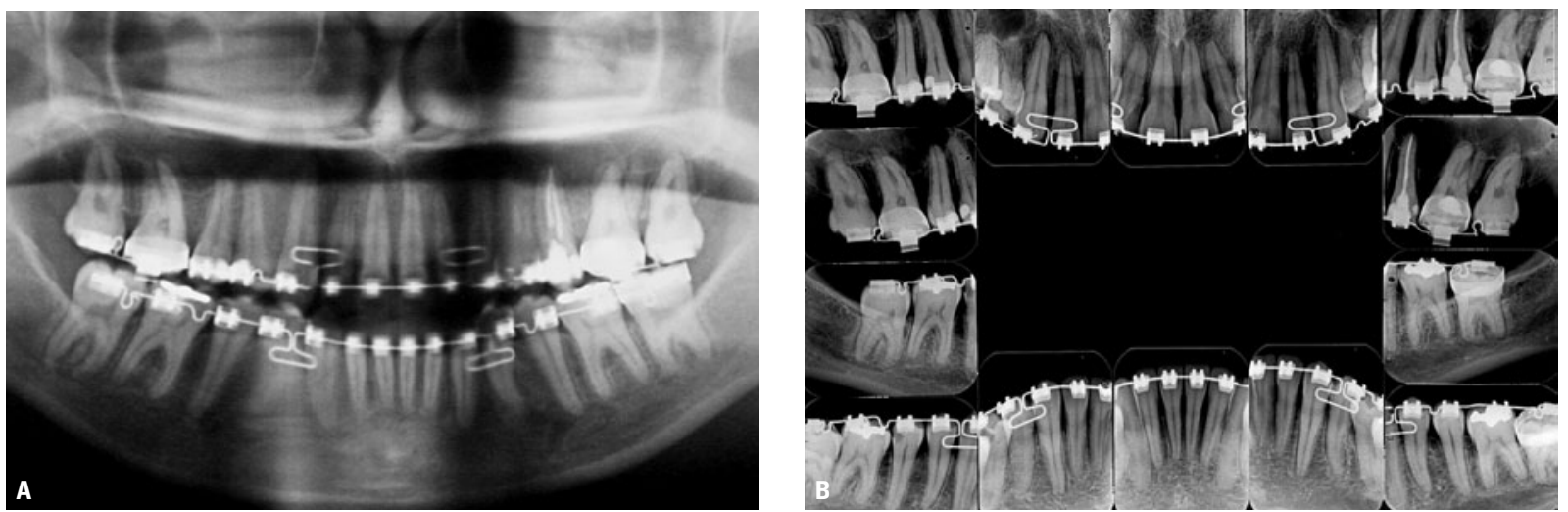

FIGURA 6 - Radiografias panorâmica (A) e periapicais (B) intermediárias.
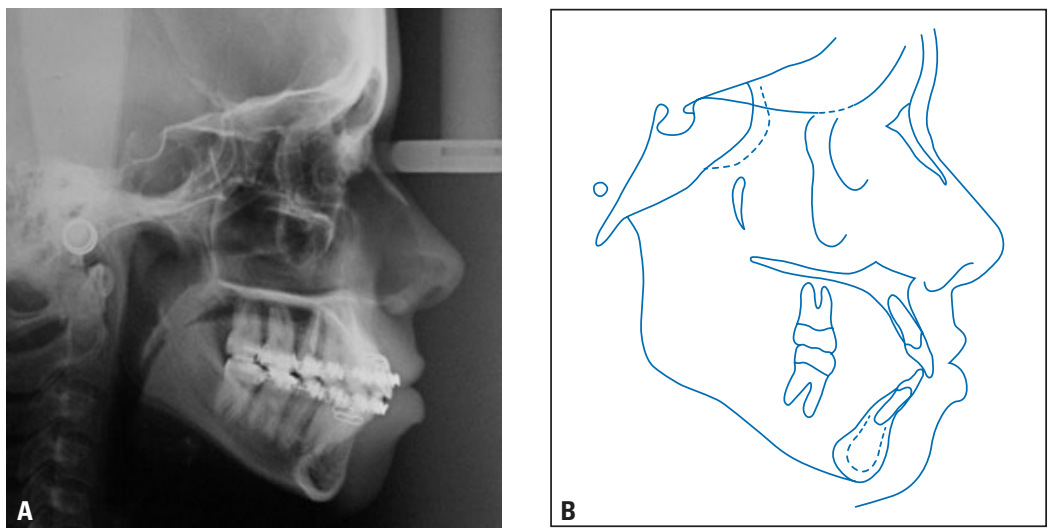

FIGURA 7 - Radiografia cefalométrica de perfil (A) e traçado cefalométrico (B) intermediários.
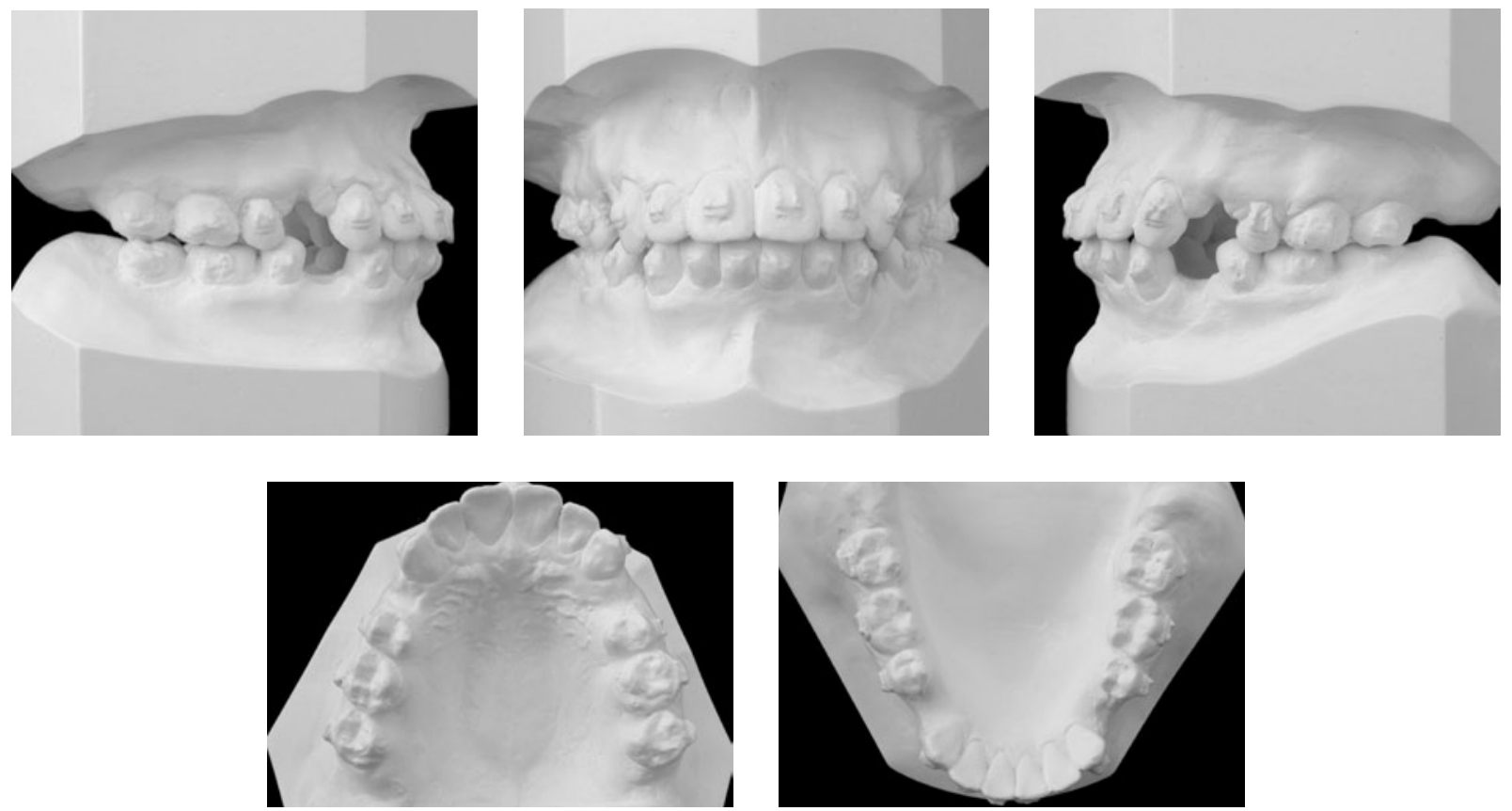

FIGURA 8 - Modelos intermediários, após a exodontia dos primeiros pré-molares superiores e inferiores. 

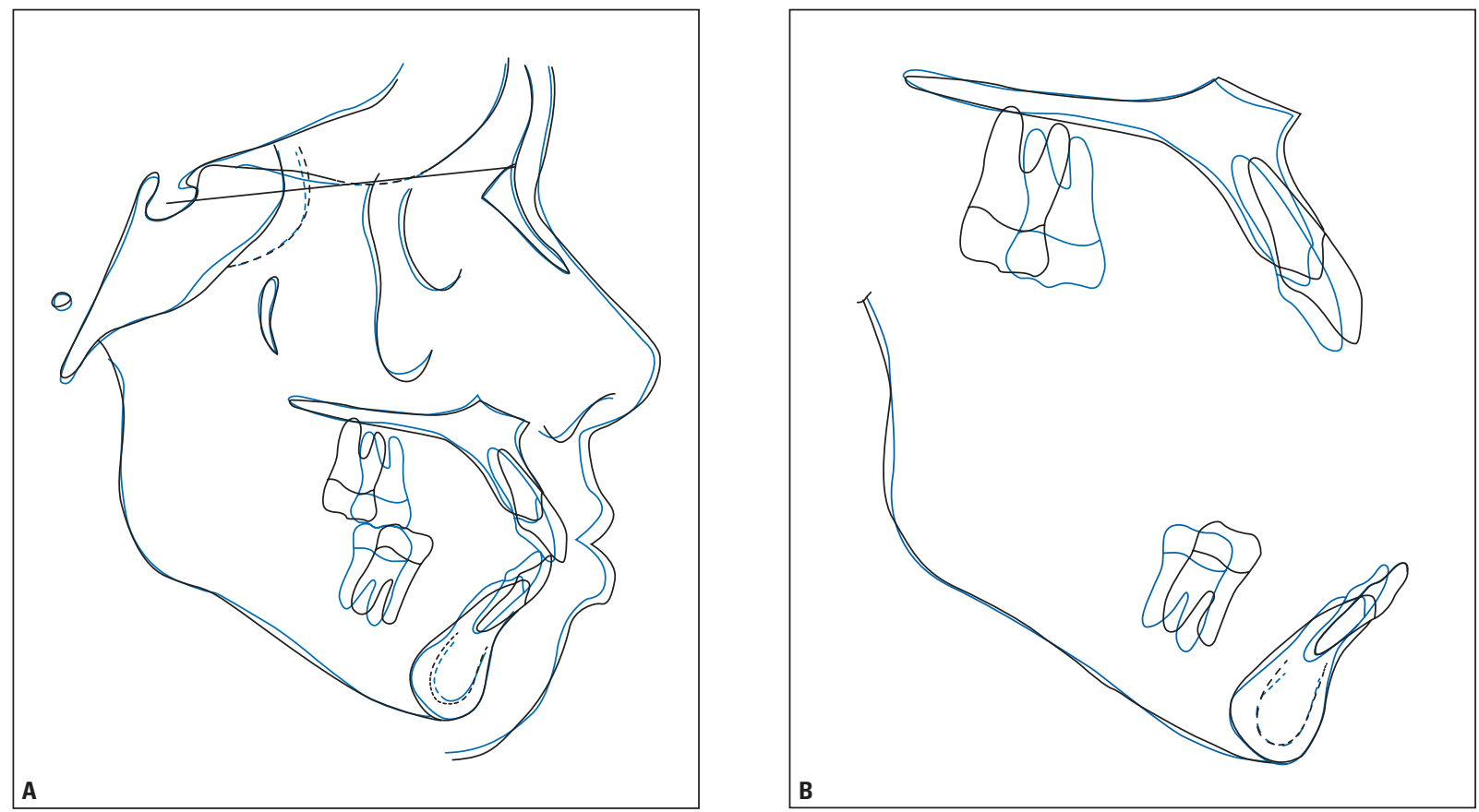

FIGURA 9 - Sobreposições total (A) e parciais (B) dos traçados cefalométricos inicial (preto) e intermediário (azul).

espaços, o caso foi finalizado com arcos 0,019" x 0,025 ", superior e inferior. Durante todo o tratamento, foi feito controle periodontal.

Após a verificação de que todos os objetivos pretendidos foram alcançados, o aparelho ortodôntico fixo foi removido, iniciando-se, então, a fase de contenção. Foi utilizada uma placa removível superior (wraparound) e uma barra inferior, confeccionada com fio Twist Flex 0,018", colada do dente 35 ao 45. A paciente utilizou a placa de contenção durante 24 horas por dia, nos primeiros 12 meses, e, após esse período, está fazendo uso noturno.

\section{RESULTADOS DO TRATAMENTO}

Avaliando-se os registros finais da paciente, pode-se verificar que todos os objetivos pretendidos foram alcançados (Fig. 10 - 13, Tab. 1). $\mathrm{Na}$ maxila, foram mantidos os posicionamentos vertical, anteroposterior e transverso da base óssea, tendo havido redução no posicionamento anteroposterior e na inclinação dos incisivos (Fig. 15). Como pode ser visto na tabela 1 , o ângulo 1-NA sofreu modificação de $30^{\circ}$ para $27^{\circ}$ e o posicionamento linear dos incisivos (1-NA, $\mathrm{mm}$ ) passou de $10 \mathrm{~mm}$ para $8 \mathrm{~mm}$, após o fechamento dos espaços dos molares (Fig. 9). Após o fechamento dos espaços dos pré-molares, a alteração no posicionamento dos incisivos superiores foi mais significativa. O ângulo 1-NA reduziu de $27^{\circ}$ para $12^{\circ}$ e o $1-N A(\mathrm{~mm})$ de $8 \mathrm{~mm}$ para $3 \mathrm{~mm}$. Essa alteração foi importante para a redução da protrusão labial (Fig. 13, 14, Tab. 1).

$\mathrm{Na}$ mandíbula, foi observado um suave giro no sentido anti-horário, com redução do ângulo FMA (Tweed) de $29^{\circ}$ para $27^{\circ}$, provavelmente, devido à grande perda de ancoragem dos terceiros molares inferiores. Do ponto de vista dentário, os incisivos foram verticalizados, com redução do ângulo IMPA (Tweed) de $108^{\circ}$ para $103^{\circ}$, após o fechamento dos espaços dos molares (Fig. 9). Após o fechamento dos espaços dos pré-molares, a alteração no 

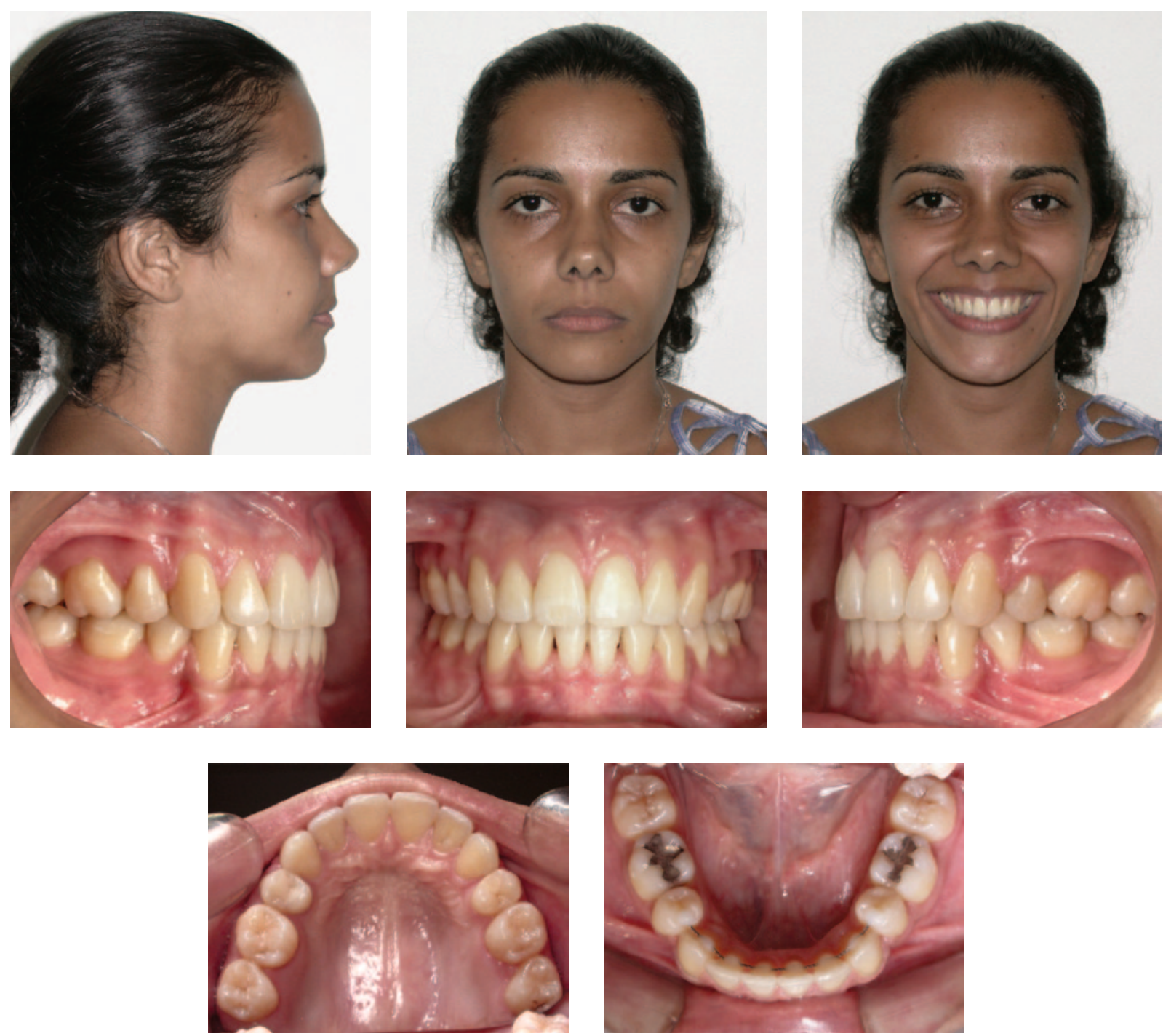

FIGURA 10 - Fotografias faciais e intrabucais finais.

posicionamento dos incisivos inferiores também foi mais significativa, passando de $103^{\circ}$ para $94^{\circ}$ (Fig. 13, 14, Tab. 1). Na avaliação linear, essa retração também foi significativa, com o 1-NB (mm) passando de $13 \mathrm{~mm}$ para $10 \mathrm{~mm}$ e, então, para $4 \mathrm{~mm}$. Clinicamente, foi obtida a relação molar de chave de oclusão dos segundos molares superiores com os primeiros molares inferiores (Fig. 10, 11), devido à grande perda de ancoragem dos segundos molares superiores e leve movimentação para distal dos primeiros molares inferiores (Fig. 15). Também, foram estabelecidos adequados trespasses horizontal e vertical, na região anterior, e contatos oclusais estáveis e simultâneos.

$\mathrm{Na}$ avaliação da radiografia panorâmica (Fig. 12A), observa-se bom paralelismo entre as raízes, com exceção das regiões entre $15 / 17$ e 25/27. As reabsorções radiculares observadas nas radiografias periapicais finais (Fig. 12B) são compatíveis com a quantidade de movimentação ocorrida. 

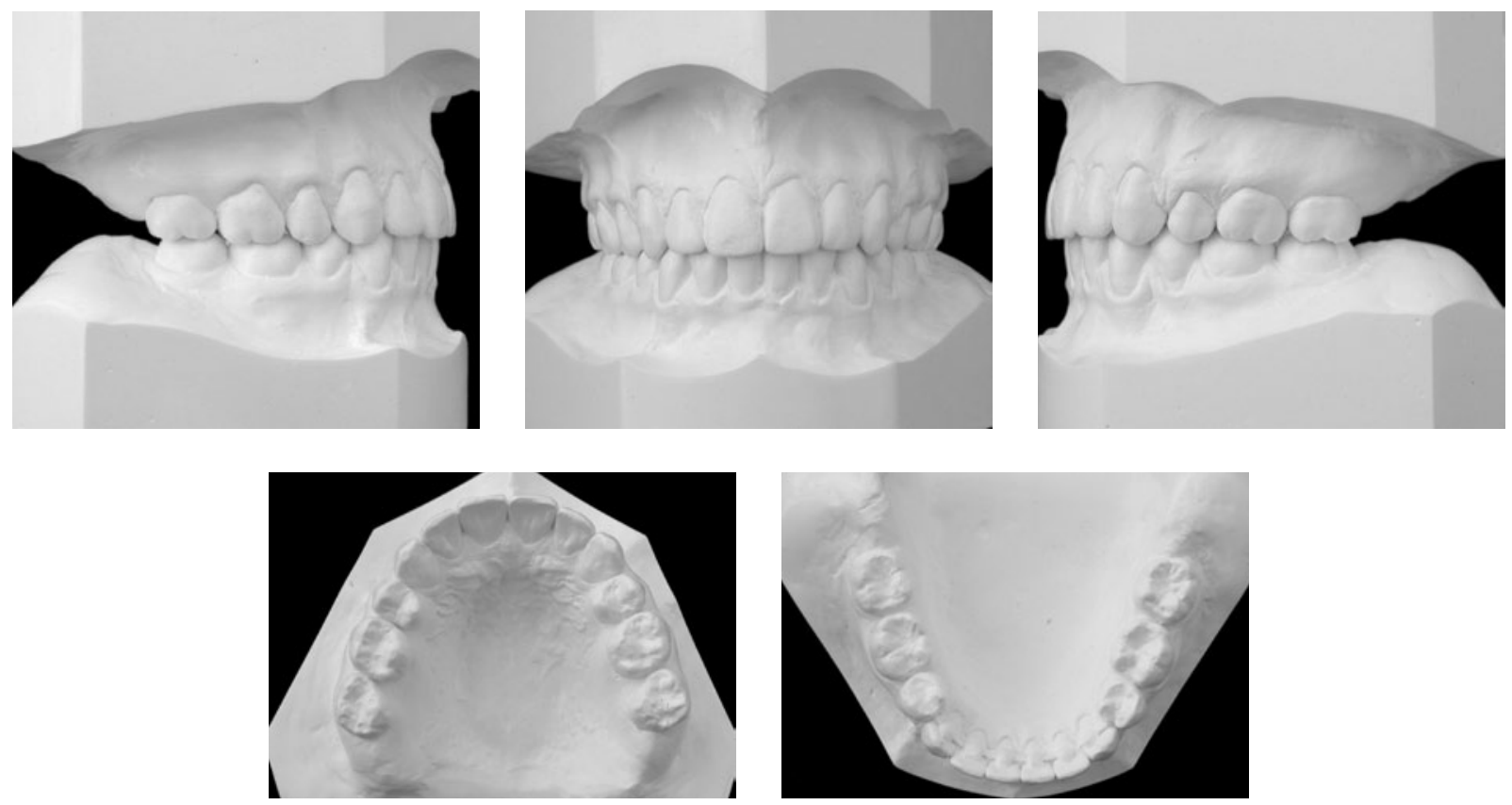

FIGURA 11 - Modelos finais.
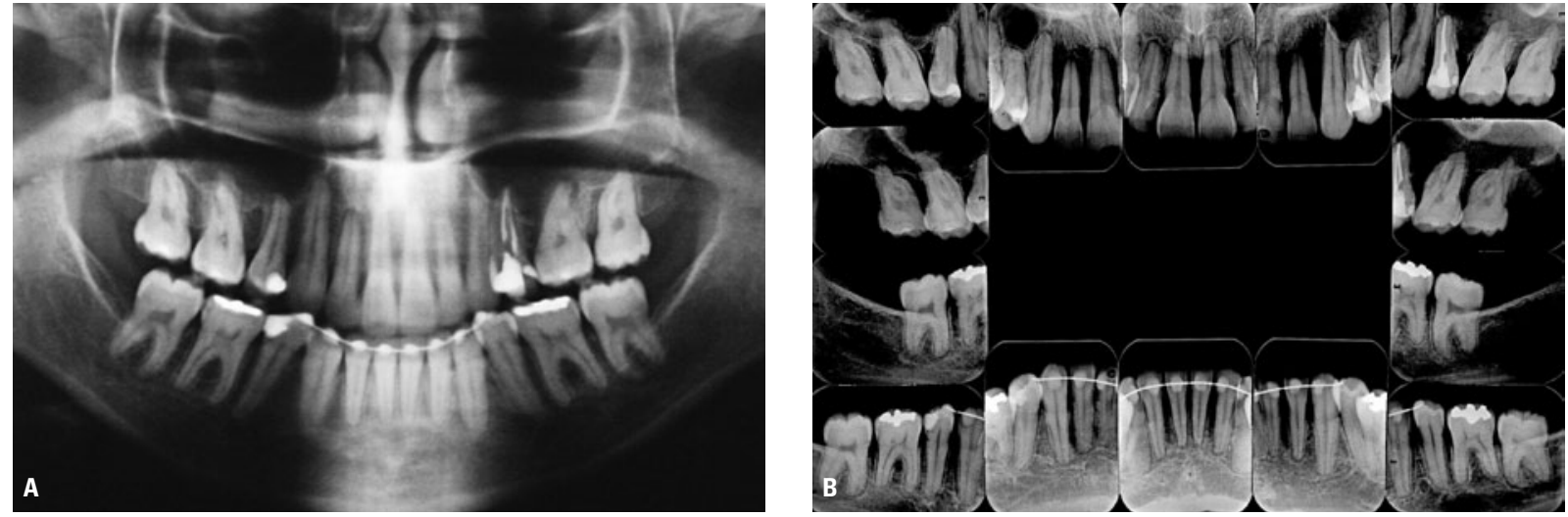

FIGURA 12 - Radiografias panorâmica (A) e periapicais (B) finais.
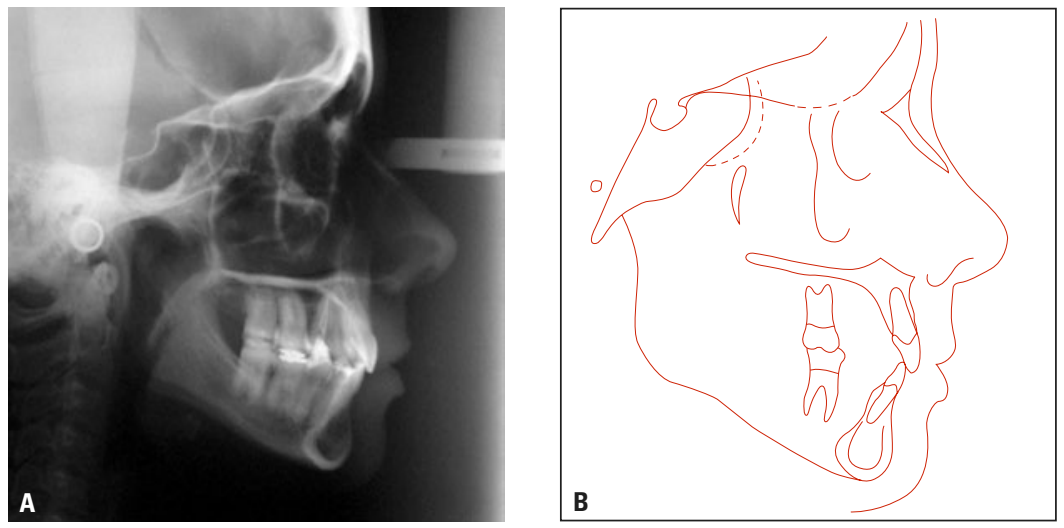

FIGURA 13 - Radiografia cefalométrica de perfil (A) e traçado cefalométrico (B) finais. 

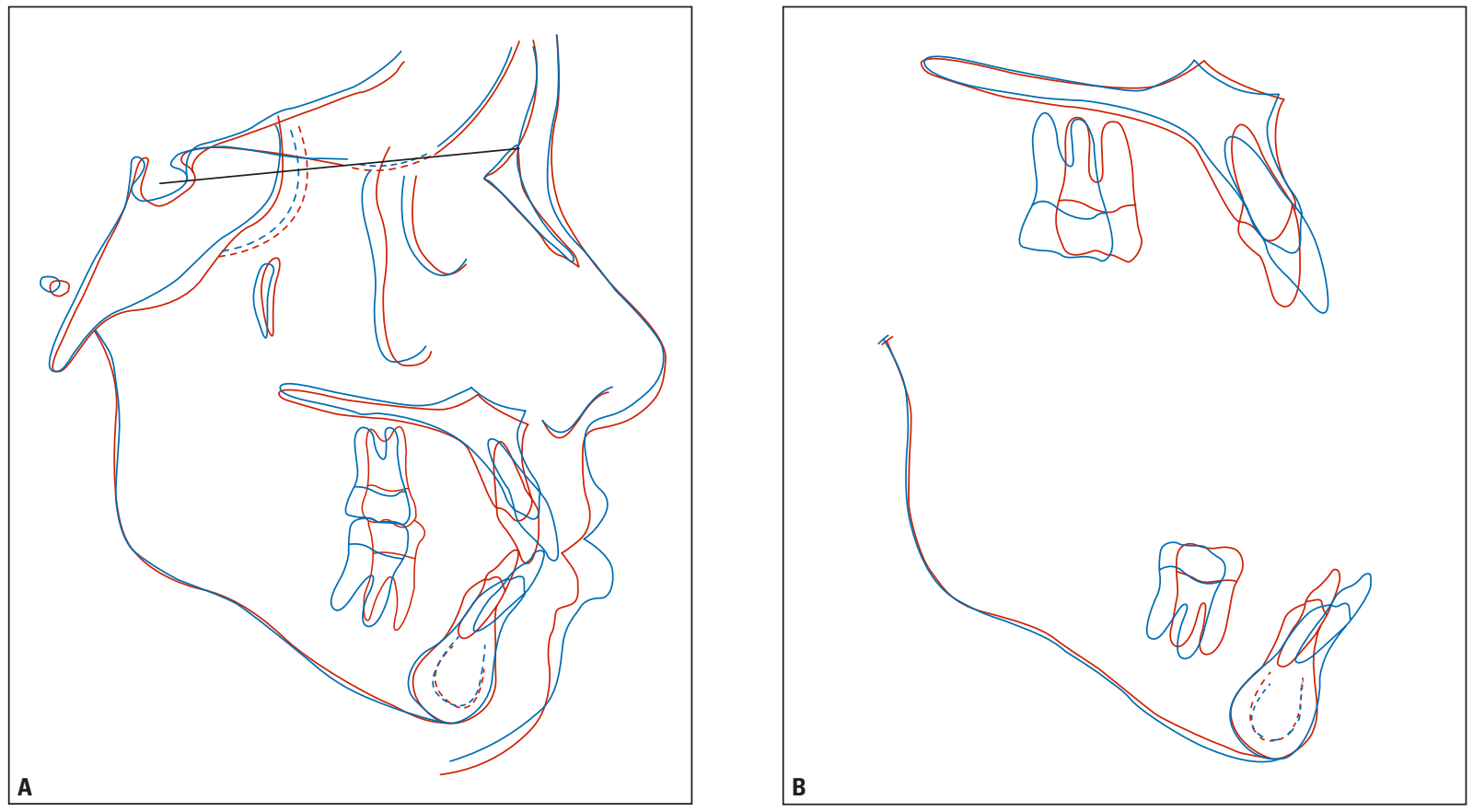

FIGURA 14 - Sobreposições total (A) e parciais (B) dos traçados cefalométricos intermediário (azul) e final (vermelho).
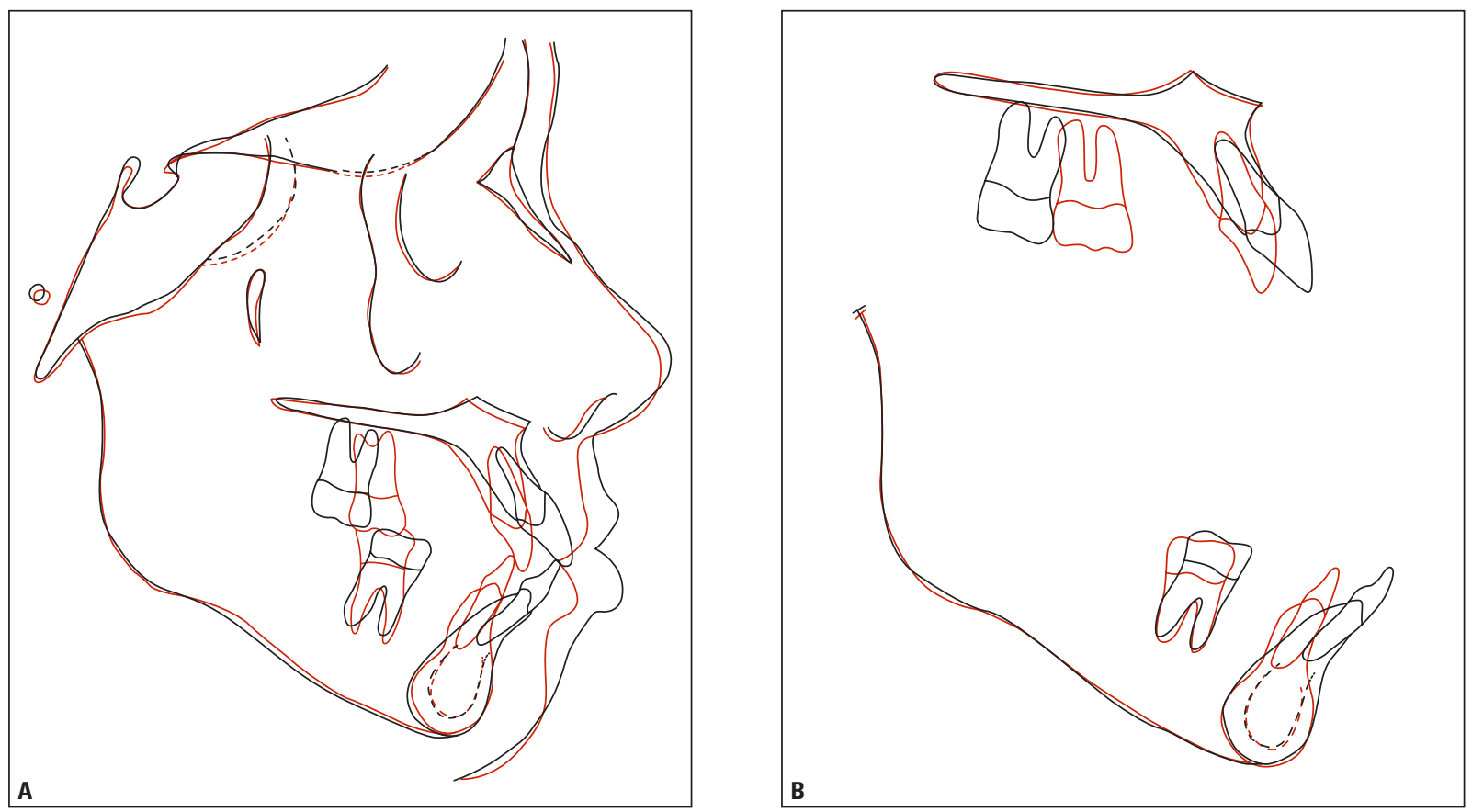

FIGURA 15 - Sobreposições total (A) e parciais (B) dos traçados cefalométricos inicial (preto) e final (vermelho). 
TABELA 1 - Resumo das medidas cefalométricas.

\begin{tabular}{|c|c|c|c|c|c|c|}
\hline & MEDIDAS & NORMAL & $\mathbf{A}$ & $\mathbf{A 1}$ & B & DIFERENÇA A-B \\
\hline \multirow{8}{*}{ 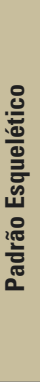 } & SNA (Steiner) & $82^{\circ}$ & $85^{\circ}$ & $85^{\circ}$ & $85^{\circ}$ & 0 \\
\hline & SNB (Steiner) & $80^{\circ}$ & $81^{\circ}$ & $82^{\circ}$ & $81^{\circ}$ & 0 \\
\hline & ANB (Steiner) & $2^{\circ}$ & $4^{\circ}$ & $3^{\circ}$ & $4^{\circ}$ & 0 \\
\hline & Ângulo de Convexidade (Downs) & $0^{\circ}$ & $9^{\circ}$ & $7^{\circ}$ & $7^{\circ}$ & 2 \\
\hline & Eixo Y (Downs) & $59^{\circ}$ & $60^{\circ}$ & $59^{\circ}$ & $59^{\circ}$ & 1 \\
\hline & Ângulo Facial (Downs) & $87^{\circ}$ & $86^{\circ}$ & $87^{\circ}$ & $87^{\circ}$ & 1 \\
\hline & SN-GoGn (Steiner) & $32^{\circ}$ & $31^{\circ}$ & $30^{\circ}$ & $31^{\circ}$ & 0 \\
\hline & FMA (Tweed) & $25^{\circ}$ & $29^{\circ}$ & $27^{\circ}$ & $27^{\circ}$ & 2 \\
\hline \multirow{7}{*}{ 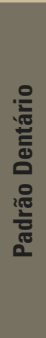 } & IMPA (Tweed) & $90^{\circ}$ & $108^{\circ}$ & $103^{\circ}$ & $94^{\circ}$ & 14 \\
\hline & 1-NA (graus) (Steiner) & $22^{\circ}$ & $30^{\circ}$ & $27^{\circ}$ & $12^{\circ}$ & 18 \\
\hline & 1-NA (mm) (Steiner) & $4 \mathrm{~mm}$ & $10 \mathrm{~mm}$ & $8 \mathrm{~mm}$ & $3 \mathrm{~mm}$ & 7 \\
\hline & T-NB (graus) (Steiner) & $25^{\circ}$ & $43^{\circ}$ & $38^{\circ}$ & $28^{\circ}$ & 15 \\
\hline & T-NB (mm) (Steiner) & $4 \mathrm{~mm}$ & $13 \mathrm{~mm}$ & $10 \mathrm{~mm}$ & $4 \mathrm{~mm}$ & 9 \\
\hline & 1/1 - Ângulo Interincisal (Downs) & $130^{\circ}$ & $104^{\circ}$ & $113^{\circ}$ & $137^{\circ}$ & 33 \\
\hline & İ-APo (mm) (Ricketts) & $1 \mathrm{~mm}$ & $11 \mathrm{~mm}$ & $8 \mathrm{~mm}$ & $1 \mathrm{~mm}$ & 10 \\
\hline \multirow{2}{*}{ 窇 } & Lábio Superior - Linha S (Steiner) & $0 \mathrm{~mm}$ & $1 \mathrm{~mm}$ & $1 \mathrm{~mm}$ & $-2 m m$ & 3 \\
\hline & Lábio Inferior - Linha S (Steiner) & $0 \mathrm{~mm}$ & $7 \mathrm{~mm}$ & $5 \mathrm{~mm}$ & $0 \mathrm{~mm}$ & 7 \\
\hline
\end{tabular}

$\mathrm{Na}$ radiografia cefalométrica de perfil (Fig. 13A), observa-se a redução da biprotrusão dentária e labial.

Com a correção da biprotrusão dentária, houve melhora significativa do perfil facial (Fig. 10, $13,15)$, com o lábio inferior passando de uma relação de $7 \mathrm{~mm}$ em relação à linha $\mathrm{S}$ (Steiner) para 0mm (Tab. 1).

\section{CONSIDERAÇÕES FINAIS}

O ortodontista tem como objetivo, ao tratar más oclusões, alcançar harmonia facial associada à oclusão excelente, sendo, para isso, necessário conhecimento da oclusão e do contorno facial equilibrado ${ }^{3}$.

O tratamento foi realizado de acordo com o planejamento. Em um primeiro momento, foram feitas as extrações dos dentes 16, 26 e 47, por apresentarem coroas com grande destruição, e do dente 37, para manter a simetria no arco inferior ${ }^{1}$. Posteriormente, foram feitas as extrações dos dentes 14, 24, 34 e 44. A tomada de decisão pela extração dos pré-molares se confirmou com a documentação intermediária, onde foi verificado que ainda havia grande protrusão dos incisivos e as raízes apresentavam integridade, permitindo, dessa forma, a continuidade do tratamento.

Existe consenso de que as alterações mais expressivas ocorridas no perfil facial, com o tratamento ortodôntico, ocorrem na região labial, após a extração dos primeiros pré-molares, seguida da retração dos incisivos ${ }^{2}$. Contudo, vários fatores devem ser considerados antes da decisão por exodontias. Esses fatores envolvem a personalidade do paciente, a estética do perfil, a convexidade, o tamanho do nariz, a posição do incisivo inferior, a tipologia facial, o padrão neuromuscular, o estado dos tecidos gengivais, a idade do paciente, o tempo de 
tratamento, a motivação do paciente, a biomecânica do tratamento, a amplitude dos deslocamentos a efetuar, as limitações clínicas, a estabilidade dos resultados obtidos, as condições de ancoragem, o crescimento facial previsto e o tipo de má oclusão ${ }^{1,4,5,6}$.

O tempo previsto para o tratamento foi de 42 meses. Contudo, houve necessidade de interrupção do mesmo em dois momentos: para o tratamento endodôntico no dente 25 e em decorrência de mudança da paciente para outro estado, que não ocorreu definitivamente. Essas duas situações provocaram o aumento no tempo de tratamento, que totalizou 51 meses. Sua conclusão foi possível em função da motivação da paciente e da boa resposta à mecânica empregada.

A estabilidade tem se tornado um objetivo essencial no tratamento ortodôntico pois, sem ela, a estética ou função ideal, ou ambas, podem ser perdidas. Como não é possível prever estabilidade a longo prazo, foi recomendado o uso prolongado da placa de contenção superior e a manutenção do fio colado nos dentes inferiores.

As reabsorções radiculares apresentadas no final do tratamento são compatíveis com a movimentação realizada, não tendo havido comprometimento periodontal.

Assim, o resultado geral pode ser considerado bom, tanto sob o ponto de vista funcional quanto da estética facial.

\title{
Angle Class I malocclusion, with severe biprotrusion, treated with permanent teeth extractions
}

\begin{abstract}
This case report describes the treatment of an Angle Class I malocclusion with dental double protrusion and with complete destruction of teeth 16,26 and 47 . The case was treated in two phases and, purposing the double protrusion correction, tooth extractions were necessary. In the first treatment phase, teeth 16, 26, 37 and 47 were extracted and, in the second phase, the extractions of 14, 24, 34 and 44 were performed. This case was presented to the Brazilian Board of Orthodontics and Facial Orthopedics (BBO), as representative of Category 4, i.e., an Angle Class I malocclusion treated with permanent teeth extractions, as part of the requirements for obtaining the BBO Diploma.
\end{abstract}

Keywords: Malocclusion, Angle Class I. Tooth extraction. Corrective Orthodontics.

\section{REFERÊNCIAS}

1. BRANDT, S.; SAFIRSTEIN, R. Different extractions for different malocclusions. Am. J. Orthod., St. Louis, v. 68, no. 1, p. 15-41, July 1975.

2. BRAVO, L. A. Soft tissue facial profile changes after orthodontic treatment with four premolars extracted. Angle Orthod., Appleton, v. 64, no. 1, p. 31-42, Jan. 1994.

3. HERSHEY, H. G. Incisor tooth retraction and subsequent profile change in postadolescent female patients. Am. J. Orthod., St. Louis, v. 61, no. 1, p. 45-54, Jan. 1972.

4. KESSLER, M. Interrelationships between orthodontics and periodontics. Am. J. Orthod., St. Louis, v. 70, no. 2, p. 154-172, Aug. 1976.

5. LANGLADE, M. Diagnóstico ortodôntico. 1. ed. São Paulo: Ed. Santos, 1993. p. 391-438.
6. MIRABELLA, A. D.: ARTUN, J. Risk factors for apical root resorption of maxillary anterior teeth in adult orthodontic patients. Am. J. Orthod. Dentofacial Orthop., St. Louis, v. 108 , no. 1, p. 48-55, July 1995.
Endereço para correspondência

Marco Antônio Schroeder

Rua Visconde de Pirajá, 444 Sobreloja 205 - Ipanema

CEP: 22.410-002 - Rio de Janeiro/RJ

E-mail: drmarco@orthonet.com.br 